\title{
2015
}

\section{DIREITO AO PARTO HUMANIZADO: EXPERIÊNCIA E LEGALIDADE NA VISÃO DAS PUÉRPERAS}

\author{
Oliveira, T.C., ; Noélia N. N. S.C
}

Curso de Enfermagem - Institutos Superiores de Ensino do CENSA - ISECENSA, Rua Salvador Correa, 139, Centro, Campos dos Goytacazes, RJ, Brasil.

O parto humanizado é um direito garantido pela Constituição Federal de 1988, e incentivado como estratégia para redução da morbimortalidade materna e neonatal, que preconiza o respeito à fisiologia do parto, à mulher, ao recém-nascido e aos familiares, bem como, a extinção de práticas intervencionistas desnecessárias na assistência obstétrica. No entanto, são verificadas barreiras na sua efetivação, o que implica na necessidade de reconhecer suas fragilidades e aprimorar a qualidade e humanização dessa assistência. O estudo teve como objetivo reunir as evidências científicas sobre as percepções da puérpera em relação à experiência do parto. Utilizou-se o método de revisão integrativa, através de pesquisa à base de dados Scielo Brasil, utilizando-se os descritores: "Direito à Saúde", "Humanização do Parto", "Legislação", com análise de 10 artigos dos últimos dez anos (2004 - 2014). Os resultados evidenciaram que os atendimentos são pautados por violência obstétrica, desrespeito aos princípios da humanização e ausência de protagonismo das parturientes, que desconhecem seus direitos e expressam insatisfação e opiniões negativas. Concluímos que as práticas de assistência humanizada ainda possuem falhas em relação ao cumprimento, fazendo-se necessários investimentos para melhorar sua qualidade.

Palavras chaves: Direito à Saúde, Humanização do Parto, Legislação

\section{REFERÊNCIAS}

ALMEIDA, C. A. L. de; TANAKA, O. Y. Perspectiva das mulheres na avaliação do Programa de Humanização do Pré-Natal e Nascimento. Rev. Saúde Pública, São Paulo , v. 43, n. 1, p. 98-104, fev. 2009 .

MALHEIROS, P. A. et al . Parto e nascimento: saberes e práticas humanizadas. Texto contexto - enferm., Florianópolis, v. 21, n. 2, p. 329-337, jun. 2012.

SILVA, L. M. da; BARBIERI, Márcia; FUSTINONI, Suzete Maria. Vivenciando a experiência da parturição em um modelo assistencial humanizado. Rev. bras. enferm., Brasília , v. 64, n. 1, p. 60-65, fev. 2011 . 


\section{5 (Jf) TACA CONHECMENIO CIENTIFICO

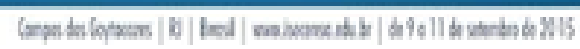

PARADA, C. M. G. L.; TONETE, V. L. P. O cuidado em saúde no ciclo gravídico-puerperal sob a perspectiva de usuárias de serviços públicos. Interface (Botucatu), Botucatu , v. 12, n. 24, p. 35-46, mar. 2008 .

DODOU, H. D. et al . A contribuição do acompanhante para a humanização do parto e nascimento: percepções de puérperas. Esc. Anna Nery, Rio de Janeiro, v. 18, n. 2, p. 262-269, jun. 2014 .

NASCIMENTO, N. M. do et al . Tecnologias não invasivas de cuidado no parto realizadas por enfermeiras: a percepção de mulheres. Esc. Anna Nery, Rio de Janeiro, v. 14, n. 3, p. 456-461, set. 2010 .

ANDREUCCI, C. B.; CECATTI, J. G. Desempenho de indicadores de processo do Programa de Humanização do Pré-natal e Nascimento no Brasil: uma revisão sistemática. Cad. Saúde Pública, Rio de Janeiro, v. 27, n. 6, p. 1053-1064, jun. 2011.

DIAS, M. A. B.; DESLANDES, S. F. Expectativas sobre a assistência ao parto de mulheres usuárias de uma maternidade pública do Rio de Janeiro, Brasil: os desafios de uma política pública de humanização da assistência.Cad. Saúde Pública, Rio de Janeiro, v. 22, n. 12, p. 2647-2655, dez. 2006.

PINHEIRO, B. C.; BITTAR, C. M. L. Expectativas, percepções e experiências sobre o parto normal: relato de um grupo de mulheres. Fractal, Rev. Psicol., Rio de Janeiro, v. 25, n. 3, p. 585-602, dez. 2013.

MACHADO, N. X. de S.; PRACA, N. de S.. Centro de parto normal e a assistência obstétrica centrada nas necessidades da parturiente. Rev. esc. enferm. USP, São Paulo, v. 40, n. 2, p. 274-279, jun. 2006 .

SERRUYA, S. J.; LAGO, T. DG.; CECATTI, J. G.. O panorama da atenção pré-natal no Brasil e o Programa de Humanização do Pré-natal e Nascimento. Rev. Bras. Saude Mater. Infant., Recife, v. 4, n. 3, p. 269-279, set. 2004 .

TEIXEIRA, N. Z. F.; PEREIRA, W. R.. Parto hospitalar: experiências de mulheres da periferia de CuibáMT. Rev. bras. enferm., Brasília, v. 59, n. 6, p. 740-744, dez. 2006.

DOMINGUES, R. M. S. M.; SANTOS, E. M. dos; LEAL, M. do C.. Aspectos da satisfação das mulheres com a assistência ao parto: contribuição para o debate. Cad. Saúde Pública, Rio de Janeiro , v. 20, supl. 1, p. S52-S62, 2004.

QUEIROZ, M. V. O. et al . Indicadores de qualidade da assistência ao nascimento baseados na satisfação de puérperas. Texto contexto - enferm., Florianópolis , v. 16, n. 3, p. 479-487, set. 2007. 